\title{
Nursery Garden Cultivation in Dunhuang Area During the Period of Tang and Five Dynasties
}

\author{
Ya Feng \\ Shijiazhuang university of applied technology ,Shijiazhuang, China \\ 457729007@qq.com
}

\section{Keywords: Dunhuang; The unearthed documents; Tang and Five Dynasties; Nursery garden}

\begin{abstract}
For a long time, Dunhuang garden planting research than the Dunhuang studies in other fields, the scholars involved in the few, very few people use a combination of the literature handed down from ancient times and unearthed documents as a system research, many readers the basic situation of Dunhuang garden is also a lack of understanding. This article through to the paperwork in Dunhuang and turfan documents preserved ancient garden planting material is comprehensive, systematic, integrated with the literature handed down from ancient times and part of the archaeological materials of information about the garden, focus on the Tang five dynasties Dunhuang region types of garden planting, management method, management type, labor status, and so on and so forth has carried on the preliminary analysis of the discussion.
\end{abstract}

\section{Introduction}

China is one of the oldest agricultural countries in the world. It has created a rich experience in agricultural practices and has formed a unique treasure trove of agricultural knowledge. Garden industry as an important part of in the field of crop planting, study of it can have a better understanding of the ancient working people material life, the production status, and to understand the status of the ancient agricultural social productivity development is of great significance, this profession has formed a consensus. Dunhuang is located at the junction of Gansu, new and Qing, and is the western end of the corridor, which is the throat of the silk road, which has been since the Han Dynasty. The beginning of the 20th century, the discovery of Dunhuang treasures, more to cause the attention of the world to Dunhuang, numerous scholars to uncover the mystery of the ancient Dunhuang and plowed, way, in politics, economy, history, geography, religion, science and technology culture in various fields is studied. The research focuses on the land system, the taxation of the corvee, the foreign trade, the economic lending, the accounting instruments, the economic and water conservancy and so on. For research in agriculture economic crops, due to the literature handed down from ancient times to the ancient garden planting extremely scarce, plus the unearthed documents related to difficulties, so few related work, and the research of scholars, mostly as a field of kinds of auxiliary content that know about our comprehensive and objective evaluation of the ancient working people material life, the condition of production has brought so much inconvenience. In this paper, combined with the literature handed down from ancient times and part of the archaeological materials, the key to Tang five dynasties Dunhuang region types of garden planting, management method, management type, labor status, and so on and so forth has carried on the preliminary analysis of the discussion, thus a deeper understanding of the ancient agricultural production and is enclosed within the walls of daily life, in the hope of the Tang five dynasties Dunhuang garden planting characteristics of context, further broaden the research scope economy, but also a certain assistance could be provided for future study. 


\section{Nursery Cultivation in Dunhuang Area in Tang and Five Dynasties}

Agriculture in Chinese ancient society in China, huaxia civilization is based on the agricultural development. Agricultural economy development has a long history, the first gathering of the agriculture is the development. Garden planting agriculture is developed from gathering, but the garden planting as an independent department of agriculture, its development has experienced from scratch, from small to large, from the field of crop planting auxiliary content gradually increased to ordinary people in daily life the important process of important agricultural department. The garden nursery is an integral part of People's Daily life.

A General Overview of Nursery Cultivation in Dunhuang Area. In the Tang five dynasty and five dynasties, the agricultural economy continued to stand out because of its unique geographical advantages and long-term stable social order. An important branch of the agricultural economy is also very active. Dunhuang garden plant species is very much, the technical characteristics of diversity, not only retained the garden since the pre-qin period the basic characteristics of agriculture, and through the part of the Dunhuang excavated documents, can be found at Dunhuang area in Tang and five dynasties in the planting of vegetables, appeared JunTian under larger garden planting situation [1].

The Tang five dynasties Dunhuang garden economy is part of agricultural economy. With the field crop planting industry, animal husbandry and economic crops such as mulberry, hemp and cotton together constitute the rebel regime economic foundation. Gardens grow in a variety of varieties, with crops and cash crops, planting trees and growing vegetables and fruit. Class of Dunhuang documents, especially the temple by account of economic document contains a lot of content about garden planting, garden plays a big role in the social economy, the monastery, government and market provides a lot of vegetables, melons and fruits, etc. At the same time to strengthen planting and management of garden, also can see in the Dunhuang documents belong to the rebel regime also set up special garden officer position [2].

The Main Types and Planting of Vegetables i in Dunhuang Area in the Tang Five Dynasties. Vegetable gardening is the most basic part of gardening. Although Dunhuang area is located in the northwest border area, rainfall is less, but rich in qilian mountain snow melt water, rich and fertile irrigation water and irrigation system YuTu soil but for vegetable planting in Dunhuang provides convenient conditions, make the Tang five dynasties Dunhuang region still a lot of vegetable varieties. It covers most of the categories recorded in medieval history books. And planting techniques are developed, all of these ensure the of the rulers, monasteries, general farmers and a large number of floating population for the supply of vegetable consumption demand. According to the unearthed documents of Dunhuang p. 2609 "Dunhuang mundane name Lin" [3], there are about a dozen of the medieval period, the main varieties of vegetables, including onion, garlic, rutabaga, Song, leek, scallions, panhu, mushrooms, ginger, mustard, Ren, lettuce, radishes, bottle gourd, alfalfa and so on more than 10 varieties. The amount and scale of these vegetables is uneven because of their eating habits and the effects of specific people's habits. Main content according to the record of the unearthed documents, this article will focus on period in Tang and five dynasties "green onion, ginger, leek, gourd" widely prevalent in hexi vegetables grown in Dunhuang area.

Onion is important in the ancient traditional vegetable varieties of a species. Since appear, has been occupies an important position in the growing of Chinese ancient garden. About the onion plant origin, recorded in the literature handed down from ancient times, there are more [4]. Onion is the Tang five dynasties Dunhuang area mainly vegetables, eat onion originally derived from wild Onions. About green edible vegetables in this sort of agricultural production reflect the Tang five dynasties period more than in the part of the Dunhuang and turfan documents, such as to rebel 
period have special planting green "green homes", the main planting green onion for the government.

Ginger is almost a household name today and has a long history of cultivation and consumption in our country. Ginger is a plant like the warm and humid climate, it's growing environment requires a certain shade and well drained soil, so in our country of the Yangtze river and pearl river basin is its best places, but the Tang five dynasties period, China's climate become warm, entered the best climate period of agricultural production. Because of the important function of diet and medicine, it is not impossible to grow the ginger in the gardens in the northwest, such as Dunhuang.

Leek in today for us is a kind of familiar with kinds of vegetables. As early as the spring and autumn period and the warring states period began with leek cultivated and edible. The northwest region is located in the remote, but from many Dunhuang turfan unearthed documents also can find a lot about the planting of leek and consumption situation [6].

Today when we understand the name and function gourd mostly had put it as a container and decorations to understand, but in the ancient society gourd is not only a kind of can make production tools, more important is one of the main vegetable varieties, gourd and melon nun leaves are edible, bowel to vegetables, can also do steamed stuffed bun, stuffed dumpling stuffing, but can't eat bitter gourd. In addition, the gourd is also a kind of edible sweet fruit. In the Tang five dynasty, the cultivation and consumption of gourds in Dunhuang in Dunhuang was also common, and its function was mainly to eat [7].

\section{The Classification and Management of the Dunhuang Garden Properties of the Tang Five Dynasty}

Tang five dynasties Dunhuang area, garden planting management before the Tang five dynasty and the basic thought, the development situation of both retained the medieval period most garden management characteristic in the central plains, at the same time as the ancient natural channel of transportation in the east and west, can very conveniently and improved quite a lot of new plant varieties, for a period of Dunhuang region agricultural economic prosperity and development to add a lot of energy. This chapter is mainly about the Tang five dynasties Dunhuang region simply garden properties and operating conditions of research, and production status of some can reflect this period unearthed material, and in the agricultural development of the Tang five dynasties Dunhuang region are summarized.

The Property of Garden Nursery in Dunhuang in the Tang Five Dynasty and the Fifth Dynasty was Divided. The Dunhuang garden of the Tang five dynasty, which inherited the Dunhuang garden and developed in the Tang five dynasty, is more mature in content and management. The garden, as part of the field, has a long history in Dunhuang. Since the land of the garden is divided into different operators, it can be attributed to all three categories: 1. The large land people in the temple run everything; Individual households operate independently. So how do these different types of business operate in the context of social history? Below, we use some of the unearthed documents and the literature to do some simple analysis.

Because of the significance of garden planting, feudal rulers even supreme ruler has always been an important part of the agricultural economy is quite seriously. Tang five dynasties period in the developing process of the feudal society during the great revolution, especially in the field of land management, a large-scale land privatization trend, Dunhuang area also through please shoot, buying and selling, exchange and other ways to realize the change of the ownership of land. In fact, the feudal government of the Dunhuang area has a long tradition of [8]. We can find the back garden of li sheng, the prince of the western cool, through the water bar of the capital of the capital 
city of sha zhou. Visible at that time not only for the purpose of government business garden garden at the corresponding level institutions edible, but also the harvest product as a tribute JinFeng to superior government, include wild celery, jujube, hu urin, etc. We can see that the Tang five dynasties Dunhuang feudal rulers garden vegetables grow relatively complete variety, basic covers the daily consumption of the main varieties of the content. At the same time, the size of the garden has not been reduced, which fully explains the unique charm of the garden. In addition, zheng binglin and other people believe that the southern and eastern cities of the city of sha zhou are the main area of the government garden, [9]. Mainly grow some economic fruit trees, including li shu yuan, pear tree garden and so on. The analysis of the location, irrigation and soil in Dunhuang area should be correct.

In the middle ages, social unrest and war, Buddhism was developed rapidly. Hexi area due to the social life for a long period of time is relatively stable, the people to live and work in peace and contentment, plus the throat of the silk road, the Dunhuang, so the spread of Buddhism in the area development more flourish. Solid rooted in the Chinese buddhist attaches great importance to the garden plant community, plus the monks in the process of long-term practice formed a non-vegetarian meals, eating all depend on the characteristics of plant-based foods, so pay more attention to religious groups of garden planting management. Tang five dynasties Dunhuang region monastery collective management and individual and the situation of the garden is very universal heritage, though not temples during this period the collective burden and the individual's daily life, but because of Buddhism have more holidays and public welfare activities, at the same time, the garden planting products sold as a commodity and career development needs of religion, so in the temple in the Tang five dynasties Dunhuang area is larger units, a wide range of garden planting operation situation, we can understand. As to when and a smaller garden planting situation of individual businesses, is a part of the small-scale peasant economy in ancient China, its management structure, variety characteristics, management technology and level, completely and ordinary yeoman farmers planting is the same.

Dunhuang out wide account class document mostly religious temples and part of government into broken through and calculate statistics, such as involving residents in cadastral is less, but can also be found in a few documents circulating. About free individual garden business varieties and management, because they did not recorded in the Dunhuang unearthed documents and the literature handed down from ancient times, this to our detailed understanding of the working people of the real situation of production and life, have to say is a great pity, but from the Dunhuang important geographical location and the rulers, the temple, and at the same time in turpan garden planting management, individual farmers in Dunhuang garden planting in kinds of business, technology and management conditions should also be more mature.

The use of the Cultivated Variety of the Dunhuang Garden Nursery in the Tang Five Dynasty. The Dunhuang gardens are grown mainly by vegetables and melons. There is no doubt that its main purpose is to eat. But due to the special geographical position, religious career developed, although the overall population, area range of a few local state county in the Tang five dynasty (the five dynasties late Tang Dynasty to rebel regime), 9-11 th-century, present the rulers in the classification of the garden has obvious all, monasteries, individual private such a situation of the three pillars of subsistence farmers. Not only that, three different properties of garden planting has unique function in place. The individual free business scale is small, mainly in order to meet the individual households for daily life, but does not rule out some of the specific management of profession of certain types of garden breeds. Government and big temple land operators to operate garden primarily for the purpose of this institution bureaucrats and temple activities of daily living 
supplies needed for the melon and fruit and vegetables. After the construction of the tubo regime, to strengthen ruling, to change sweet policies promoting tribe will be all, so in some paperwork reflects a strange phenomenon: should the lane this religious institutions edible vegetables were secular institutions "pedestrian tribe" and "silk wadding tribe" and so on, this reflects the period in Tang and five dynasties commodity exchanges, especially food vegetable circulation is without limit. Government agencies to operate the garden of harvest, in addition to meet the needs of the department, may also into to the superior department, hexi area due to the abundant and "grapes". The taste is delicious, and it has been used as a local specialty for the imperial court, which can also be seen in the literature.

\section{The Identity and Management of Laborers in the Dunhuang Garden of the Tang Five Dynasty}

There are three types of properties planted by the Dunhuang garden in the Tang five dynasty: all the feudal government; All the temple; All individual family. The first two planting scale is compared commonly big, of the individual family garden planting management with limited land, planting and quantity of the relatively small size of many, but does not rule out some garden was growing profession, etc. Bing-lin zheng [11] in the 'Tang five dynasties Dunhuang wastelands economic research article based on the analysis of the study of related documents: large-scale garden plant mainly distributed around the melon, the sand, state, city, their basic in nature are owned by the feudal rulers or temple, in the garden, the main engaged in productive labor is a kind of unique name producers - garden, the garden is a major technical gardener, are the main participants in the garden planting and management. In addition also found in the documents for these larger garden manage workers and families of the garden, some employees and shortly thereafter. The smaller garden belong to the individual family. But its origins and management situation is more complicated: or from some own limited land subsistence farmers, they are the main stakeholders, government tax male plow female weave, lived a self-sufficient life, has a very limited number of garden land. Or does not have its own land, a long period is attached to the feudal rulers or feudal temple, engaged in heavy pastoral work. Use the surplus labor time business proprietary, similar to the temple door or permanent people type operators; Or the number of Dunhuang area rely on large land owners of land management on loan tenant farmers in the garden. Can be seen from the above analysis, the Tang five dynasties Dunhuang area of garden mode of operation can be divided into the following three ways: employment type, the word type, tenancy type, etc.

\section{Conclusion}

China boasts the birthplace of ancient agricultural civilization, and the development of crop farming is still a source of pride for the Chinese people today. The emergence, development and perfection of the garden industry in ancient China underwent a long period of evolution. Dunhuang is located in the northwestern China, is an important bottleneck of the ancient eastern and western exchanges, its geographical environment, such as water and irrigation conditions, the social change in Tang and five dynasties, garden planting in planting species, management technology, Labour management way still retains the characteristics since the middle ages, as a result of Dunhuang special geographical location and rich religious beliefs, so on the operation characteristics and operation properties significantly with local characteristics. These for us to study and grasp the material life of the working people in ancient agricultural society, the condition of production is of great significance. This article through to the paperwork in Dunhuang and turfan documents preserved 
ancient garden planting material is comprehensive, systematic, integrated with the literature handed down from ancient times and part of the archaeological materials of information about the garden, garden planting from before Tang society review, focus on the Tang five dynasties Dunhuang region types of garden planting, management method, management type, labor status, and so on and so forth has carried on the preliminary analysis of the discussion, has a certain practical significance.

\section{References}

[1] Dunhuang social and economic literature, the second edition, pp. 41-411.

[2] B.L.Zheng. Research on the history of the military in Dunhuang[M].lanzhou university press, 1997.

[3] Dunhuang treasure122, page 428.

[4] Dunhuang treasure no. 46, pp. 637.

[5] "the unearthed document in turpan," page 274.

[6] "the unearthed document of turpan," the third book, page 310, artefacts press, 1981.

[7] 'Dunhuang treasure' 128, page 458.

[8] J.B.Liu "from Dunhuang documents to see the development of the private land of the five generations", the "history of China agriculture", the second period of 2006.

[9] B.L.Zheng. "special research on the history of the righteous army in Dunhuang".

[10] qi Chen jun 'Dunhuang and population' (sequel)

[11] B.L.Zheng. "special research on the history of the righteous army in Dunhuang". 